\title{
EDITORIAL \\ Crisis, pandemia y derechos humanos
}

\author{
Claudia Iriarte Rivas \\ Universidad de Chile
}

Como decíamos meses atrás en el editorial del primer número de este año del Anuario de Derechos Humanos, la crisis y emergencia sanitaria nos planteó la necesidad de un debate y una mirada multidimensional en torno a los derechos humanos. Debate y mirada que buscaban y buscan dar respuesta, desde una perspectiva de derechos humanos, a los agudos problemas que la emergencia sanitaria deja a la vista.

Sin embargo, la problemática y los desafíos que para el país ha implicado la emergencia sanitaria desde un punto de vista social y sobre todo en materia de derechos humanos, no debe abordarse como una crisis particular y específica: sus urgencias, problemas y dificultades deben entenderse como parte de una crisis mayor, la de la institucionalidad y agotamiento del modelo constitucional y de derechos, el cual se perfiló desde el golpe de Estado en 1973 y se configuró e institucionalizó con la Constitución de 1980.

El agotamiento del modelo constitucional y del sistema de derechos se había venido evidenciando desde el inicio de las movilizaciones sociales en el año 2006, con la denominada «revolución pingüina», que cuestionó la falta de reconocimiento del derecho a la educación y la regulación mercantilizada que de ésta se hacía en la Ley Orgánica Constitucional de Educación, vigente en ese momento.

Luego, ha habido diversas movilizaciones sociales que han puesto en el debate público la crítica a la ausencia o déficit en el reconocimiento de los derechos fundamentales y sus garantías. Las principales demandas han sido los derechos a la educación, a la salud y a la seguridad social, los reclamos medioambientales, el cuestionamiento del modelo de desarrollo económico, el reconocimiento de derechos de los pueblos indígenas, la igualdad y no discriminación de la mujer.

La movilización social iniciada en octubre del año pasado y que se ha mantenido de modo ininterrumpido hasta hoy marca un punto de inflexión en este proceso. Aquí ya no hay demandas acotadas o particulares, sino que se plantea la crisis estructural de la institucionalidad y la necesidad imperiosa de poner fin a la Constitución 
de 1980. Se sostiene la necesidad de una nueva constitución $-\mathrm{y}$ de su institucionalidad- estructurada sobre un sistema de derechos fundamentales y de garantías que esté en concordancia con el Sistema Internacional de Derechos Humanos.

A partir de marzo de este año, la crisis de agotamiento del modelo constitucional quedó subsumida - incluso por algunos olvidada - bajo la emergencia, urgencia y gravedad de la crisis sanitaria. Es cierto que la pandemia ha puesto al país frente a desafíos extraordinarios en materia de salud, económica y social; sin embargo, también en este contexto particular, la incapacidad de ofrecer respuestas satisfactorias - mínimamente satisfactorias en muchos casos - tiene directa relación con la problemática, los déficits, las ausencias y las discriminaciones que en materia de derechos ha implicado e implica el sistema de derechos fundamentales y sus garantías, tal cual se encuentran recogidos y regulados en la Constitución de 1980 y en la legislación complementaria.

Las graves situaciones que se han presentado en el manejo de la crisis sanitaria se han agudizado por el carácter subsidiario del Estado que se establece en la Constitución en lo referente al cumplimiento de sus fines y mandato. Lo anterior queda de manifiesto en las débiles herramientas y recursos tanto de política pública, de infraestructura, de institucionalidad estatal y presupuestarios con que cuenta el Estado para enfrentar una crisis de esta magnitud. Esto es especialmente grave en el desarrollo de una institucionalidad que permita la garantía y el ejercicio de derechos fundamentales, que en la actualidad están entera o parcialmente privatizados, como es el caso de la salud, la educación, la vivienda y la seguridad social.

La falta de sustancialidad en el reconocimiento del derecho a la salud y, por lo mismo, de un sistema de garantías importante, ha implicado un lento pero sostenido deterioro del sistema público de salud, tanto primario como de especialidades, y en particular a nivel de atención de urgencia y pacientes críticos. Esta realidad quedó en evidencia a fines de junio, cuando se liberaron por primera vez los datos del Departamento de Estadísticas e Información de Salud (DEIS) de muertes por covid-19 a nivel municipal. En la Región Metropolitana, la mayor cantidad de muertes del año 2020, comparado con el promedio de los últimos cinco años, se explica en su totalidad como resultado del covid-19. La Pintana, Cerro Navia y San Ramón - tres de los cuatro municipios declarados más vulnerables en 2019- están en los tres primeros lugares de las comunas que exhiben un incremento de fallecidos en la Región Metropolitana entre abril y septiembre de 2020, con tasas de aumento superiores al 65\%; por el contrario, de los diez municipios mejor evaluados en el Índice de Prioridad Social para la región, ocho presentan cifras de exceso de mortalidad significativamente menores que el promedio de la capital. Entre abril y septiembre, el porcentaje para la región fue de 44,9\%; en Santiago fue de 43,4\%; Vitacura, 31,7\%; La Reina, 22,17\%; Providencia, $17,9 \%$; y Nuñoa, $15,43 \%$. Esta última tuvo sólo un tercio del promedio 
de la región, y alcanzó un poco más de un quinto del porcentaje de aumento en San Ramón, que fue de $74,60 \%{ }^{1}$

Hasta la fecha, no se ha logrado implementar un sistema robusto de trazabilidad de los casos de covid-19, ya que no se cuenta con recursos económicos para implementar equipos humanos y técnicos que se integren y refuercen el nivel de atención primaria, de modo de desarrollar un modelo de trabajo coordinado, sistemático y eficiente. Se trata de lograr un seguimiento y control efectivo de las personas que han arrojado resultados positivos en los exámenes de covid-19, de modo de hacer un trabajo de prevención y control - en caso de que haya sospecha de contagio-con las personas con que hayan tenido contacto estrecho.

En materia de acceso a la educación, durante este año, todo el sistema educacional se ha paralizado. Niños, niñas, adolescentes, universitarios y universitarias han debido asistir a clases en línea, ya sea en forma sincrónica o asincrónica. Cualquiera sea la vía para participar de esta modalidad de enseñanza, se requiere, al menos, contar con un dispositivo electrónico, conexión a internet y en lo posible un espacio mínimamente tranquilo para seguir con atención las clases. Demás está decir que en la gran mayoría de los hogares no se dan de manera satisfactoria estas condiciones. A lo más hay uno o dos celulares por grupo familiar, los más «acomodados» dispondrán además de un computador o tablet, y el internet al que se accede es inestable y limitado - muchos vimos la foto de la estudiante universitaria que trabajaba desde el techo de su casa, único lugar donde había buena señal-. En cuanto a disponer de un espacio de tranquilidad para estudiar, si se considera que cerca del $60 \%$ de los hogares en Chile no excede los $70 \mathrm{~m} 2$, con grupos familiares promedio de 4,1 personas, es evidente que ese requisito es ilusorio en una mayoría de hogares en el país. Un dato más para graficar la desigualdad: las comunas con soluciones habitacionales más precarias tienen una media de $12,5 \mathrm{~m} 2$ por persona, la media en las comunas de mayores recursos es de 30,2 $\mathrm{m} 2$ por persona. Es evidente que las condiciones de hacinamiento afectan no sólo el acceso al derecho a la educación, sino que también el cumplimiento de las medidas básicas para evitar la propagación del virus.

En lo referente al derecho al trabajo y el acceso a ingresos mínimos y medios de subsistencia, las medidas de protección del empleo no se sustentaron en un rol dinamizador o sostenedor del sistema productivo por parte del Estado. Se limitaron a proteger el vínculo laboral y a permitir un ingreso con cargo al fondo del subsidio de cesantía del propio trabajador o trabajadora. Estas medidas no son aptas para mantener el acceso de medios de subsistencia autónomos a través del ejercicio del derecho

1. Cifras del Departamento de Estadísticas e Información de Salud del Ministerio de Salud, publicadas en: Sebastián Rivas, «Santiago: La fuerte alza de muertes en las comunas más pobres de la capital», $L a$ Tercera, 18 de octubre de 2020, disponible en https://bit.ly/34Q3ptA. 
al trabajo y, en la mayoría de los casos - debido a lo bajo de los montos acumulados en el fondo de cesantía-, tampoco permiten satisfacer las necesidades asociadas al derecho a la alimentación, agua y vivienda. La falencia de estas medidas llevó al Congreso a impulsar proyectos de ley que han permitido a trabajadores y trabajadoras acudir a los fondos de acumulación individual para pensiones de vejez e invalidez, en retiros equivalentes al 10\% cada vez. Esta solución nuevamente recae en los propios asalariados y, además, complejiza el debate sobre la reforma al sistema de seguridad social en Chile.

De cara al proceso constituyente que se ha iniciado, y teniendo en consideración las crisis que se han analizado brevemente en estas líneas, parece importante precisar, aunque sea de manera somera, cuatro puntos que, a mi juicio, son centrales en el debate que viene y cuya consideración permitiría superar parte de los agudos problemas que presenta el actual sistema de derechos y garantías establecido en la Constitución de 1980.

Primero, la configuración de la constitución sobre la base de renovados principios, que recojan los principios de libertad e igualdad junto al principio de solidaridad, de modo de asegurar el desarrollo integral y digno de la personalidad humana como consecuencia y goce común de los derechos humanos.

Segundo, nuevos fines del Estado, que, junto con garantizar el ejercicio de los derechos fundamentales, consideren la promoción de condiciones y la remoción de obstáculos para la vigencia efectiva y no sólo formal de los derechos fundamentales, las libertades y garantías respecto de todos y todas.

Tercero, el sistema de derechos y garantías debe fundarse en el Sistema Internacional de los Derechos Humanos, de modo que la institucionalidad jurídica nacional se pueda enriquecer del avance y desarrollo que tiene en forma permanente este sistema de derechos.

Por último, el reconocimiento de derechos y el sistema de garantías no debe estar circunscrito al catálogo de derechos y garantías, sino que debe ser estructurante y transversal respecto de todo el nuevo orden constitucional, lo que significa abordar la Constitución - y la estructuración del Estado- como un sistema de derechos y garantías, considerando a su vez el orden normativo que la complementa. 
El Anuario de Derechos Humanos es una publicación semestral de referencia y consulta en materia de derechos humanos y campos afines. Busca ser un espacio de discusión de los temas centrales en el ámbito nacional e internacional sobre derechos humanos. Es publicado desde 2005 por el Centro de Derechos Humanos de la Facultad de Derecho de la Universidad de Chile.

\author{
EDITORA \\ Claudia Iriarte Rivas \\ ciriarter@derecho.uchile.cl \\ SITIO WEB \\ anuariocdh.uchile.cl \\ CORREO ELECTRÓNICO \\ anuario-cdh@derecho.uchile.cl \\ LICENCIA DE ESTE ARTÍCULO \\ Creative Commons Atribución Compartir Igual 4.o Internacional
}

\author{
\% \\ La edición de textos, el diseño editorial \\ y la conversión a formatos electrónicos de este artículo \\ estuvieron a cargo de Tipográfica \\ (www.tipografica.io)
}

